\title{
A Model for Planning Wagonload Freight Transport under Relative Uncertainty
}

\author{
Tadeusz Cisowski', Łukasz Wojciechowski², Jarosław Zubrzycki ${ }^{*}$, Arkadiusz Małek ${ }^{3}$ \\ 1 Military University of Aviation, Dywizjonu 303 Street 35, 08-521 Dęblin, Poland \\ 2 Department of Mechanical Engineering, Lublin University of Technology, Nadbystrzycka 36, 20-618 Lublin, \\ Poland \\ 3 Department of Transportation and Informatics, University of Economics and Innovation in Lublin, Projektowa \\ 4, 20-209 Lublin, Poland \\ * Corresponding author's e-mail: j.zubrzycki@pollub.pl
}

\begin{abstract}
The study presents a mathematical model for the development of an optimal wagon transport plan in conditions of relative uncertainty. It describes an algorithm that allows searching for an optimal railroad-blocking plan in an environment of approximate initial data. The algorithm is based on the branch-and-bound method and fuzzy intervals. An example is provided of how an optimal transport plan for wagon flows given in this way can be determined.
\end{abstract}

Keywords: wagon flows, transport plan, branch-and-bound method, fuzzy sets

\section{INTRODUCTION}

The advantages of the railways as a mean of transport are indisputable. Contrary to road transport, trains do not pollute the air to such a large extent, they relieve the roads by reducing traffic jams, and they are a safer and cheaper mean of transport than road vehicles [8]. Especially at longer distances - over $300 \mathrm{~km}$ - freight rail transport is cheaper than road transport. In Poland, but also in the European Union, which is very dependent on oil imports from third countries, one more fact speaks in favour of railways. Trains are powered by electricity [6], which may be mostly or even fully produced on the basis of domestic energy resources - coal or renewable energy sources [14]. This cannot be said about motor fuels because there is still a long way to market dominance of cars with electric or hydrogen propulsion [12]. New solutions for energy saving and monitoring are used in the railway infrastructure as well as in the trains themselves $[35,36]$.
For all these reasons, the EU authorities have been emphasizing on the development of railways for years. In 2011, the European Commission already set a target for the Member States to transfer more than half of road freight transport over $300 \mathrm{~km}$ to other means of transport - mainly rail - by 2050 .

This EU policy also results from the fact that in Western Europe for several decades (in Poland and Central and Eastern Europe from the 1990s), the railroad was in retreat [2,22]. After the motorization was popularized, the European preferred using their own cars rather than trains, and European companies, transporting their goods, increasingly chose more comfortable trucks instead of railways [5]. The truck is able to pick up the cargo from anywhere and deliver it to any place. The same cannot be said for the freight transported by trains, which usually have to be reloaded onto cars and then transported to their destination. This, in turn, not only extends the transport time, but also makes it more expensive [9]. 
The effect is that in many countries the share of railways in the transport market has gradually decreased. Even Germany, one of the most proecological and pro-railway countries in the world, could not cope with it. In Poland, the share of railways in the transport of goods decreased at first and remained at the same level within the last decade (18-19\%) and only recently it has started to increase. Against this background, Poland is still conspicuous being one of the EU leaders in terms of the share of railways in freight transport. In our country, it amounts to 25.6 percent. However, it must not be forgotten that in 2005 it was $37 \%$ and, unfortunately, it continues to decline while the share of road transport is growing. For several years, the amount of goods transported by rail in Poland has been fluctuating and, basically, has not increased [4]. In 2017, this amount was 240 million tonnes, i.e. as much as, for instance, in 2009, but much less than in the years 2004-2008, when it reached 280-290 million tonnes per year, and then, for the following years, it would be maintained again at a much lower level (220-250 million tons per year) [41].

It is also worth mentioning that in the years 1990-2015, the railway in Poland experienced an evident collapse: its transport decreased by almost 40 percent during this time. An important reason for this is the excessive transport rates, as well as the too slow average speed of freight trains in Poland and major timetable setbacks [33]. This is due to the condition of the railway infrastructure and numerous railway investments are currently underway. Satellite navigation can also be used to manage rail transport [39]. This can contribute to increasing the reliability of rail services [37]. Several countries from Eastern Europe have plans to develop their regional and international rail networks [43, 40]. These include Poland [41], Slovakia [21], the Czech Republic [38] and Hungary [43].

If the condition of the railway infrastructure improves in the future, the high rates for track use will remain [28]. In Poland, a model has been adopted that the costs of maintaining the railway infrastructure are to be covered by the carriers who use it and pay for it. It's a healthy model, however, the problem is that in order for more carriers to transport goods by rail instead of roads, incentives and facilitations are needed [5]. For example, after 1989, many sidings in Poland were liquidated, due to which trains could go directly to production plants [41].
Thus, a government program with incentives to restart these sidings and build new ones would be effective. In the case of resumption of operation of railway sidings it is necessary to determine the optimal organization of wagon transport [23]. The quality of the organization and technology of wagon transportation largely determines the attractiveness of rail freight.

The railway has very good development prospects, as many Polish and foreign research institutions conduct research on computer-aided development of railway infrastructure [11] and diagnostics of existing railway connections [17, 18] with the use of unmanned aerial vehicles [10]. More and more innovative solutions are being implemented on the railways, which increase its attractiveness [20, 34]. Innovative rail networks and innovative means of rail transport are being developed [42]. Increasing the safety of rail transport is a very important area of research [30]. It also covers cybersecurity [26].

The issue of the optimal organization of wagon transport has been sufficiently and widely described in many works $[7,21]$. The system analysis of this task, the complexity of its solution and the shortcomings of the existing methodologies are presented in [16].

It should be noted that all virtual solutions to this task are heuristic and do not provide optimality. Among the existing methods of selecting the optimal wagon transport organization, the absolute calculation method deserves special attention, as it played a key role in the development of the theory and practice of wagon flow organization. This method presents a diagram of a complete review of possible solution and allows to determine the optimal solution while limiting the number of processing stations to 10 .

The paper [16] presents the computer-oriented approach in the search for the optimal plan of wagon flow organization for a large railway network. However, it should be noted that in the existing methods of determining the optimal wagon transportation plan, there are no real limitations resulting from the number of station tracks and the processing capacity of the stations themselves. This leads to the necessity of adjusting the existing plans, which is an extremely difficult task due to its combinatorial nature.

In [15], the application of a mathematical model using linear programming with mixed integers was considered to solve the problem of vehicle route planning [27]. The model aims to 
establish distribution routes from the distribution center to each customer in order to reduce the transport costs associated with these routes. The study took into account the use of a fleet of different capacity in the distribution network, which has the specific characteristics of a star network and which must meet various efficiency criteria [19], such as meeting the requirements of each customer, vehicle load capacity, work schedule, and sustainable usage of resources [24]. The idea is to find the right amount of equipment to meet the demand, and, thus, improve the level of customer service, optimize the use of human and economic resources in the area of distribution, and the maximum use of vehicle capacity [29]. A mathematical model for a case study of linear MILP programming with mixed integers was presented as well as a corresponding numerical study.

The article [1] presents the issue of Railway Rescheduling Problem (RRP) as the problem of finding a new train timetable after one or several events by minimizing a certain measure of this effect, e.g. total delay. In order to model this problem, two complementary formulations have been proposed: Mixed Integer Programming (MIP) and constrained programming (CP). Due to the impossibility of solving real instances with standard solvers, several solution methods have been proposed: rescheduling the shift to the right; local search method based on MIP; Statistical Analysis of Propagation of Incidents (SAPI); and the CP approach.

The article [13] describes and develops a mathematical model of the distribution of empty wagons for loading at a railway junction. This model takes into account the requirements of wagon owners in terms of the use of their wagons, the level of operation of the railway stations of the transport node and the possibility of adding groups of empty wagons to interchange [31], cleaning and industrial trains running on a tight schedule. The developed model and software package were implemented in the IT system of the industrial railway of the large metallurgical company OJSC «Magnitogorsk Metallurgical Works», which supports up to two thousand wagons belonging to different owners. This model made it possible to reduce the workload of dispatching operations planning the distribution of empty wagons for loading and to reduce the total time spent by wagons in the company's railway system.
Typically, models of wagonload freight transport plans are deterministic ones. The deterministic models require precise information on what values all the parameters of a task will take in a future period for which the optimal railroad blocking (train formation) plan is being developed.

A statistical deterministic model has limited application because the execution of rail transport activities may differ from previously adopted assumptions. Moreover, models of optimal wagon flow management with exact parameter values may turn out to be highly "approximate", because very often the data are not the parameters themselves but sets of possible parameter values [32]. For this reason, it is more practical to look for optimal decisions by assigning possible values rather than specific numbers to parameters. The topic of wagon flow management under relative uncertainty has barely been explored in the literature on wagonload freight transport planning [25].

In this present study, a branch-and-bound algorithm was used to search for an optimal railroad blocking plan, with parameters given as interval values and simultaneous minimization of the objective function.

\section{MATHEMATICAL MODEL OF THE PROBLEM}

It was assumed that the daily flows of wagons $P_{i j}(i, j=1 \div n$ where $i$ - departure station, $j-$ arrival station) are given by an fuzzy interval type (L-R) in some (non-empty) space $u$. This type of interval is a parametric representation of a fuzzy interval with an upper semi-continuous membership function, and it is a combination of two types of function $\mathrm{R}^{*} \rightarrow[0,1]$, marked with the letters $\mathrm{L}$ and $\mathrm{R}$. $\mathrm{L}$ is an upper semi-continuous decreasing function, which satisfies the following conditions: $L(0)=1$, and also $\forall u>0, L(u)<1 \forall u<1, L(u)>0$,

$$
L=0 \text { or } L(u)>0, \forall u \text { and } L(+\infty)=0
$$

An L-function (or an R-function) that satisfies these conditions is called a form function. The membership function of a fuzzy interval $\mathrm{M}$ can be represented by two functions, $\mathrm{L}$ and $\mathrm{R}$, and four parameters: $(\bar{m}, \underline{m}) \in \mathrm{R}^{2}-$ kernel of fuzzy interval (Fig. 1 and 2) and $\alpha, \beta \geq 0$ - left and right fuzziness coefficients, given by: 


$$
\mu_{p}(u)=\left\{\begin{array}{c}
L\left(\frac{\underline{m}-u}{\alpha}\right) \text { if } u \leq \underline{m} \\
1 \text { if } \underline{m} \leq u \leq \bar{m} \\
R\left(\frac{u-\bar{m}}{\beta}\right) \text { if } u \geq \bar{m}
\end{array}\right.
$$

It is convenient to divide wagon flows into two classes depending on their size. A first class consists of small flows, including null flows, i.e $P_{i j}=$ 0 . A second class encompasses large flows, i.e. $P_{i j}$ $\neq 0$. Thus, a wagon flow $P_{i j}$ can be represented as an $(\mathrm{L}-\mathrm{R})$ fuzzy interval of the following type: $P_{i j}$ $=(\underline{m}, \bar{m}, \alpha, \beta)_{L R}$. The functions $\mathrm{L}$ and $\mathrm{R}$ are of the form $L\left(\frac{\underline{m}-u}{\alpha}\right)=1-(1-h)\left(\frac{\underline{m}-u}{\alpha}\right)$ if $0 \leq u \leq \underline{m}$, where $h$ is the degree of likelihood that a given wagon flow $N_{i j}=0 ; 0 \leq h \leq 1 ; R\left(\frac{u-\bar{m}}{\beta}\right)=1-\left(\frac{u-\bar{m}}{\beta}\right)$ if $u \geq \bar{m}$. Fuzzy first and second-class wagon flows are shown in Figures 1 and 2.

For the first class of wagons it is assumed that $h=0$. Let the shortest route between two vertices of graph $\mathrm{G}$ be denoted by $M_{i j}$.

In this study, wagon flow size is expressed as an interval to take account of real-life instability of and fluctuations in railroad freight volumes. Wagon-hour savings for one wagon moved from station $i$ through station $j$ without processing is also shown as an $(\mathrm{L}-\mathrm{R})$ fuzzy interval with a kernel of most feasible values for a given station $t_{i j}=(\underline{t}, \bar{t}, \alpha, \beta)_{L R}$. It is also assumed that $t_{i j}=0$, i.e. $t_{i j}$ is a real number belonging to $\mathrm{R}$. Then $t_{i j}=(0$, $0,0,0)_{L R}, \forall L, R$.
Wagon-hour accumulation $(\mathrm{cm})_{i j}$ related to assembling, on station $i$, a train serving one origin-destination (OD) pair and travelling towards station $j$ is also given by an $(\mathrm{L}-\mathrm{R})$ fuzzy interval. It is known that $(\mathrm{cm})_{i j}=(\mathrm{cm})_{i p}$, where $(i, p)-$ first arc of route $M_{i j}$.

Savings $T_{i i}$. associated with the movement of one wagon without processing, when the OD pair $(i, j)$ is singled out (branched off):

$$
T_{i j}=\sum_{\substack{L \in M_{i j} \\ L \neq j}} t_{i L}
$$

here, the sum applies to all stations located on the shortest route $M_{i j}$ between stations $i$ and $\mathrm{j}$, and is calculated as a sum of fuzzy numbers.

A sum of two (L-R) fuzzy intervals $M=(\underline{m}, \bar{m}, \alpha, \beta)_{L R} \quad$ and $\quad N=(\underline{n}, \bar{n}, \gamma, \delta)_{L R}$ is of the following form $[1,3,4,5]: M+N=$ $(\underline{m}+\underline{n}, \bar{m}+\bar{n}, \alpha+\gamma, \beta+\delta)_{L R}$. Given this, savings $T_{i j}$ associated with the movement of one wagon, without processing, when the OD pair $(i, j)$ is branched off, also constitute an (L-R) fuzzy interval. Assuming that each wagon $P_{i j}$ flow should be processed as fast as possible, we obtain total processing wagon-hours $\sum_{i, j} P_{i j} t_{i j}^{\Sigma}$, where $t_{i j}^{\Sigma}$ is the length of the shortest route $M_{i j}^{N}$ between stations $i$ and $j$ in the graph of processing operations $\mathrm{N}$ and is given by $t_{i j}^{\Sigma}=\sum_{L \in M_{i j}^{N}} t_{i L}$. Also note that the operation of multiplication in sum $\sum_{i, j} P_{i j} t_{i j}^{\Sigma}$ involves fuzzy numbers $\left(P_{i j}\right.$ and $t_{i j}^{\Sigma}$ - fuzzy intervals). According to $[1,3,4,5]$, multiplication of

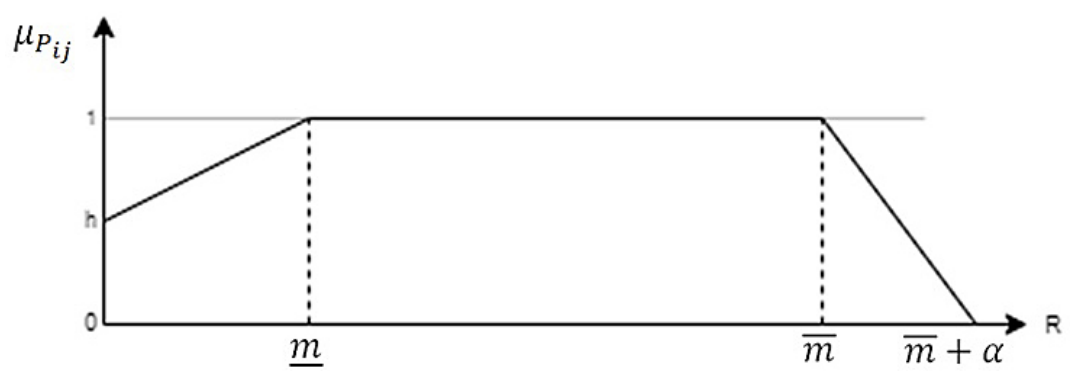

Figure 1. A fuzzy wagon flow that can take a zero value

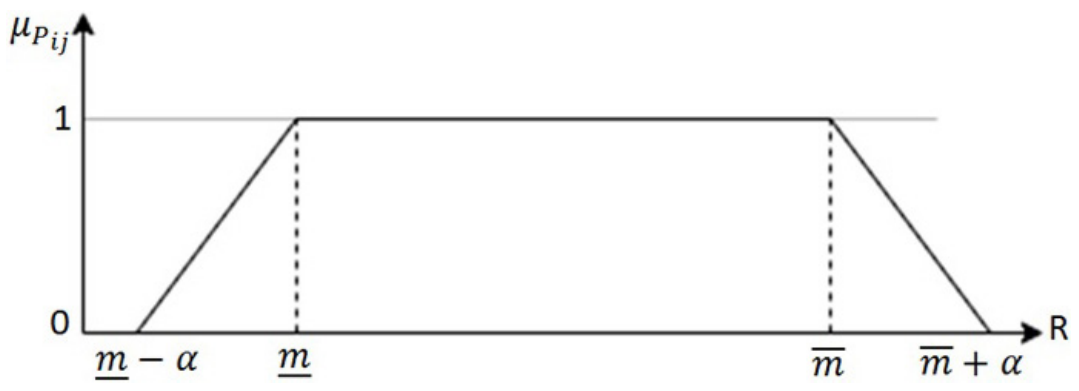

Figure 2. A fuzzy wagon flow that does not take a zero value 
(L - R) fuzzy intervals $M=(\underline{m}, \bar{m}, \alpha, \beta)_{L R}$ and $N$ $=(\underline{n}, \bar{n}, \gamma, \delta)_{L R}$ takes the following form:

$$
\begin{gathered}
N \cdot N=(\underline{m n}, \overline{m n}, \underline{m n}-(\underline{m}-\alpha)(\underline{n}-\gamma), \\
(\underline{m}+\beta)(\underline{n}+\delta)-\underline{m n}_{L R} .
\end{gathered}
$$

The objective function $F\left(n_{i j}\right)$ describing the wagon-hours of accumulation and processing of wagons has the following form:

$$
F\left(n_{i j}\right)=\sum\left((c m)_{i j} n_{i j}+P_{i j} t_{i j}^{\Sigma}\left(n_{i j}\right)\right) \rightarrow \min _{\left\{n_{i j}\right\}}
$$

where:

$$
n_{i j}=\left\{\begin{array}{c}
1 \text { if OD pair }(i, j) \text { exists } \\
0 \text { otherwise }
\end{array}\right.
$$

Function (1) will be used later on in this paper to solve a discrete programming problem using the branch-and-bound method. The estimate of the objective function (1) is:

$$
\begin{aligned}
\lambda_{S}^{k} & =\lambda\left(G_{S}^{k}\right)=\sum_{i, j}(c m)_{i j} n_{i j}\left(N_{S(k)}^{k}\right)+ \\
& +\sum_{i, j} P_{i j} t_{i j}^{\Sigma}\left(N_{S(k)}^{k} \cup \widetilde{N}_{S(k)}^{k}\right)
\end{aligned}
$$

where: $G_{S}^{k}$ is one of the subsets created in the k-th branching step, $N_{S(k)}^{k}$ is a set of OD pairs included in the optimal plan in the k-th step of branching, and $\widetilde{N}_{S(k)}^{k}$ is a set of OD pairs analysed in the k-th step of branching.

Set $N_{S(k)}^{k}$ is the set of necessary OD pairs in the k-th step of branching. Set $\widetilde{N}_{S(k)}^{k}$ includes any OD pair that does not belong to $N_{S(k)}^{k}$ and meets the following condition:

$$
F\left(N_{S(k)}^{k} \cup(i, j)\right)>F\left(N_{S(k)}^{k}\right)
$$

where: $>$ is a preference symbol.

Each estimate of the objective function (1) is an $(\mathrm{L}-\mathrm{R})$ fuzzy interval. The estimates are compared in the following way: in accordance with the possibility theory, fuzzy intervals $\mathrm{M}$ and $\mathrm{N}$ are compared using indices of possibility and necessity of fuzzy events. To find those indices, the possibility and necessity of fuzzy events are determined $(N,+\infty)$ and $(N,+\infty)$ for the distribution function $\mu_{m}$.

This gives us four dominance indices:

1.

$$
\begin{aligned}
& B_{M}([N,+\infty))=B(\bar{X} \geq \underline{Y})= \\
= & \sup _{\min }\left(\mu_{M}(u), \quad \sup (v \leq u)\right)= \\
= & \sup _{u \geq v} \min \left(\mu_{M}(u), \mu_{N}(v)\right)
\end{aligned}
$$

- possibility that interval $M$ is not smaller than $N_{i}$
2. $B_{M}((N,+\infty))=B(\bar{X}>\bar{Y})=$

$$
\begin{aligned}
& =\underset{u}{\operatorname{supmin}}\left(\mu_{M}(u), \inf \left(1-\mu_{N}(v)\right)\right)= \\
& =\begin{array}{c}
\sup \inf \min \\
u v>u
\end{array}
\end{aligned}
$$

- possibility that interval $M$ is larger than $N_{i}$

$$
\begin{aligned}
& \text { 3. } H_{M}([N,+\infty))=H(\underline{X} \geq \underline{Y})= \\
& ={ }_{u}^{\operatorname{infmax}}\left(1-\mu_{M}(u), \sup _{v \leq u} \mu_{N}(v)\right)=
\end{aligned}
$$$$
=\inf _{u} \sup _{\leq v}^{\max }\left(1-\mu_{M}(u), \mu_{N}(v)\right)
$$

- necessity that interval $M$ is not smaller than $N_{i}$

4. $H_{M}((N,+\infty))=H(\underline{X}>\bar{Y})=$

$$
\begin{aligned}
& =\operatorname{infmax}_{u}\left(1-\mu_{M}(u), \inf \left(1-\mu_{N}(v)\right)\right)= \\
& =1-\sup _{u \leq v} \min \left(\mu_{M}(u), \mu_{N}(v)\right)
\end{aligned}
$$

- necessity possibility that interval $M$ is larger than $N_{i}$

$\mathrm{B}$ are possibility measures, and $\mathrm{H}$ are necessity measures [4]. In the case of (L-R) fuzzy intervals, determining the four indices (4-7) leads to finding the points of intersection of their membership functions. For instance, if $M=(\underline{m}, \bar{m}, \alpha, \beta)_{L R}$ and $N=(\underline{n}, \bar{n}, \gamma, \delta)_{L R}$, then expressions (4-7) take the following form:

$B(\bar{X} \geq \underline{Y})=\max (0, \min (1,1+(\bar{m}-\underline{n}) /(\beta+\gamma)))$

- dominance possibility

$H(\underline{X} \geq \underline{Y})=\max (0, \min (1,(\underline{m}-\underline{n}+\gamma) /(\alpha+\gamma)))$

- dominance necessity

$B(\bar{X}>\bar{Y})=\max (0, \min (1,(\bar{m}-\bar{n}+\beta) /(\beta+\delta)))$

- strict dominance possibility

$H(\underline{X}>\bar{Y})=\max (0, \min (1,(\underline{m}-\bar{n}) /(\alpha+\delta)))$

- strict dominance necessity

It is easy to notice that formulas (8-11) are not true when the sum of fuzziness coefficients is 0 , i.e. when $\mathrm{M}$ and $\mathrm{N}$ are regular closed intervals. In that case, the zero fuzziness coefficients should be replaced with positive coefficients belonging to interval $(0,1)$ so that the membership functions intersect at a point whose Y-coordinate lies outside interval $[0,1]$. Moreover, the following operations are true:

if $\bar{m}=\underline{n}, \beta+\gamma=0$, then, to calculate $B(\bar{X} \geq \underline{Y})$, coefficients $\beta, \gamma$ can be replaced with any positive number; 


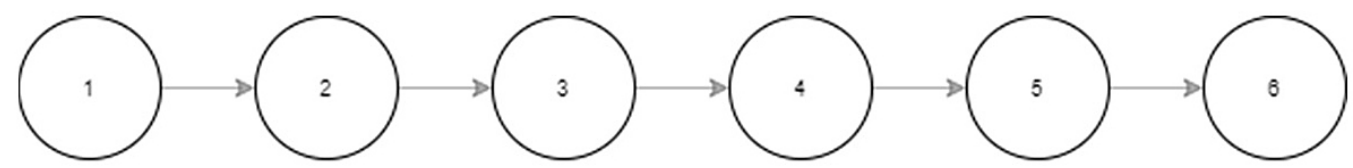

Figure 3. Region of a railway network

Table 1. Wagon flows

\begin{tabular}{|c|c|c|c|c|c|c|}
\hline$P_{i j}$ & 1 & 2 & 3 & 4 & 5 & 6 \\
\hline 1 & - & $100,100,0,0$ & $180,220,10,10$ & $75,85,2,2$ & $90,110,5,5$ & $190,210,2,2$ \\
\hline 2 & - & - & $100,100,0,0$ & $270,330,10,10$ & $18,22,2,2$ & $70,90,2,2$ \\
\hline 3 & - & - & - & $100,100,0,0$ & $18,22,2,2$ & $145,155,5,5$ \\
\hline 4 & - & - & - & - & $100,100,0,0$ & $48,52,2,2$ \\
\hline 5 & - & - & - & - & - & $100,100,0,0$ \\
\hline 6 & - & - & - & - & - & - \\
\hline
\end{tabular}

if $\underline{m}=\bar{n}, \alpha+\delta=0$, then, to calculate $H(\underline{X}>\bar{Y})$, coefficients $\alpha, \beta$ can be replaced with any positive number;

$$
\begin{aligned}
& \text { if } \underline{m}=\underline{n}, \alpha+\gamma=0 \text {, then } H(\underline{X} \geq \underline{Y})=0 ; \\
& \text { if } \bar{m}=\bar{n}, \beta+\delta=0 \text {, then } B(\bar{X}>\bar{Y})=0 .
\end{aligned}
$$

\section{Example [2]}

Determine an optimal railroad blocking plan under relative uncertainty for a railway network region shown in Figure 3. Fuzzy wagon-hours of accumulation $\mathrm{cm}_{i j}=(980,1020,5,5)$, where $i, j=$ 1,6. Fuzzy wagon flows are shown in Table 1 . The savings of wagon-hours for wagons moved without processing have the following fuzzy values:

$$
\begin{gathered}
t_{21}=(3,5,1,1) ; t_{32}=(2,4,1,1) ; \\
t 43=2,4,1,1 ; t 54=3,5,1,1 .
\end{gathered}
$$

Each vertex of the solution tree (Fig. 4) features a set of OD pairs $\widetilde{N}_{S(k)}^{k}$ in the top line, and estimate values in the bottom line $\lambda_{S}^{k}=\lambda\left(G_{S}^{k}\right)$. The numbers on the arcs denote the OD pairs that have been added to the set of optimal OD pairs. Moreover, Figure 4 shows the order of vertices that leads to the optimal solution.

Step zero. In this step, the set of singled out OD pairs contains only those that make up point-to-point routes (direct OD pairs). To determine the set of OD pairs $\widetilde{N}_{1}$ that satisfy condition (3), we compare the value of the objective function defined in the set of direct OD pairs $N_{1}$ with the values of the objective function for sets $N_{1} \cup(i, j)$, where OD pairs $(i, j)$ originate from a set of indirect wagon flows $\left\{P_{i j}\right\}$. We calculate the value of the objective function for set $N_{1}$ :

$$
\begin{gathered}
F\left(N_{1}\right) \sum_{i, j}\left((c m)_{i j} n_{i j}+P_{i j} t_{i j}^{\Sigma}\right)= \\
=(4900,5100,25,25)+ \\
+(5452,11484,2333,2973)= \\
=(10352,16352,2958,2998)
\end{gathered}
$$

Then, we created all possible sets of type $B(\bar{X} \geq \underline{Y})$ and determine the values of the objective function for them. The results of these calculations are shown in Table 2.

The data in Table 2 demonstrate that at step zero, all OD pairs satisfy the necessary condition. The dominance indices show that:

- at index values higher than 0.5 , interval $\mathrm{X}$ is significantly larger than interval $\mathrm{Y}$;

- at H-index values $H(\underline{X} \geq \underline{Y})>0.3$ and B-index values $B(X>Y)>0.7$, interval $\mathrm{X}$ is significantly larger than interval $\mathrm{Y}$.

Index values $H(\underline{X}>\bar{Y})=0$ and $B(\bar{X} \geq \underline{Y})$ $=1$ mean that intervals $X$ and $Y$ partly or fully overlap. Formulated in this way, vertex 1 of Fig. 4 contains the following OD pairs $(1,3),(1,4)$, $(1,5),(1,6),(2,4),(2,5),(2,6),(3,5),(3,6),(4,6)$. The lower bound of the objective function for vertex 1 is estimated as follows:

$$
\begin{gathered}
\lambda_{1}=\lambda\left(G_{1}\right)=\sum_{i, j}(\mathrm{~cm})_{i j} n_{i j}\left(N_{1}\right)+ \\
+\sum_{i, j} P_{i j} t_{i j}^{\Sigma}\left(N_{1} \cup \widetilde{N}_{1}\right)=(4900,5100,25,25) .
\end{gathered}
$$

Step one. We define the possible sets containing OD pairs included in vertex 1 and OD pairs sequentially added to them, from among the OD pairs belonging to vertex 1 . Through branching, 
Table 2. Value of objective function and dominance indices for vertex 1

\begin{tabular}{|c|c|c|c|c|c|}
\hline \multirow{2}{*}{$(i, j)$} & Values $F\left(N_{1} \cup(i, j)\right)$ & \multicolumn{4}{|c|}{ Dominance indices } \\
\cline { 3 - 6 } & & $B(\bar{X} \geq \underline{Y})$ & $H(\underline{X} \geq \underline{Y})$ & $B(\bar{X}>\bar{Y})$ & $H(\underline{X}>\bar{Y})$ \\
\hline$(1,3)$ & $(9727,141479,1790,2264)$ & 1 & 0.582 & 0.969 & 0 \\
\hline$(1,4)$ & $(9557,13959,1626,2094)$ & 1 & 0.608 & 1 & 0 \\
\hline$(1,5)$ & $(9372,13444,1495,1931)$ & 1 & 0.642 & 1 & 0 \\
\hline$(1,6)$ & $(9432,13824,1591,2049)$ & 1 & 0.672 & 1 & 0 \\
\hline$(2,4)$ & $(9906,14216,1627,2041)$ & 1 & 0.520 & 1 & 0 \\
\hline$(2,5)$ & $(9860,14148,1605,2029)$ & 1 & 0.529 & 1 & 0 \\
\hline$(2,6)$ & $(9512,13704,1567,2039)$ & 1 & 0.613 & 1 & 0 \\
\hline$(3,5)$ & $(10270,15168,1814,2304)$ & 1 & 0.454 & 0.832 & 0 \\
\hline$(3,6)$ & $(9307,13509,1525,1994)$ & 1 & 0.662 & 1 & 0 \\
\hline$(4,6)$ & $(9973,15069,1888,2430)$ & 1 & 0.534 & 0.831 & 0 \\
\hline
\end{tabular}

Table 3. Value of objective function and dominance indices for vertex 2

\begin{tabular}{|c|c|c|c|c|c|}
\hline \multirow{2}{*}{$(i, j)$} & \multirow{2}{*}{ Values $F\left(N_{2} \cup(i, j)\right)$} & \multicolumn{4}{|c|}{ Dominance indices } \\
\cline { 3 - 5 } & & $B(\bar{X} \geq \underline{Y})$ & $H(\underline{X} \geq \underline{Y})$ & $B(\bar{X}>\bar{Y})$ & $H(\underline{X}>\bar{Y})$ \\
\hline$(1,4)$ & $(9997,13879,1431,1819)$ & 1 & 0.360 & 0.701 & 0 \\
\hline$(1,5)$ & $(9587,12939,1221,1559)$ & 1 & 0.452 & 0.995 & 0 \\
\hline$(1,6)$ & $(9017,11889,1027,1337)$ & 1 & 0.617 & 1 & 0 \\
\hline$(2,4)$ & $(9991,13731,1423,1757)$ & 1 & 0.361 & 0.749 & 0 \\
\hline$(2,5)$ & $(10071,13643,1331,1657)$ & 1 & 0.314 & 0.791 & 0 \\
\hline$(2,6)$ & $(12512,15190,2061,2439)$ & 1 & 0.227 & 0.274 & 0 \\
\hline$(3,5)$ & $(9645,13063,1246,1507)$ & 1 & 0.437 & 0.960 & 0 \\
\hline$(3,6)$ & $(8862,11404,958,1260)$ & 1 & 0.729 & 1 & 0 \\
\hline$(4,6)$ & $(9418,13054,1322,1698)$ & 1 & 0.545 & 0.731 & 0 \\
\hline
\end{tabular}

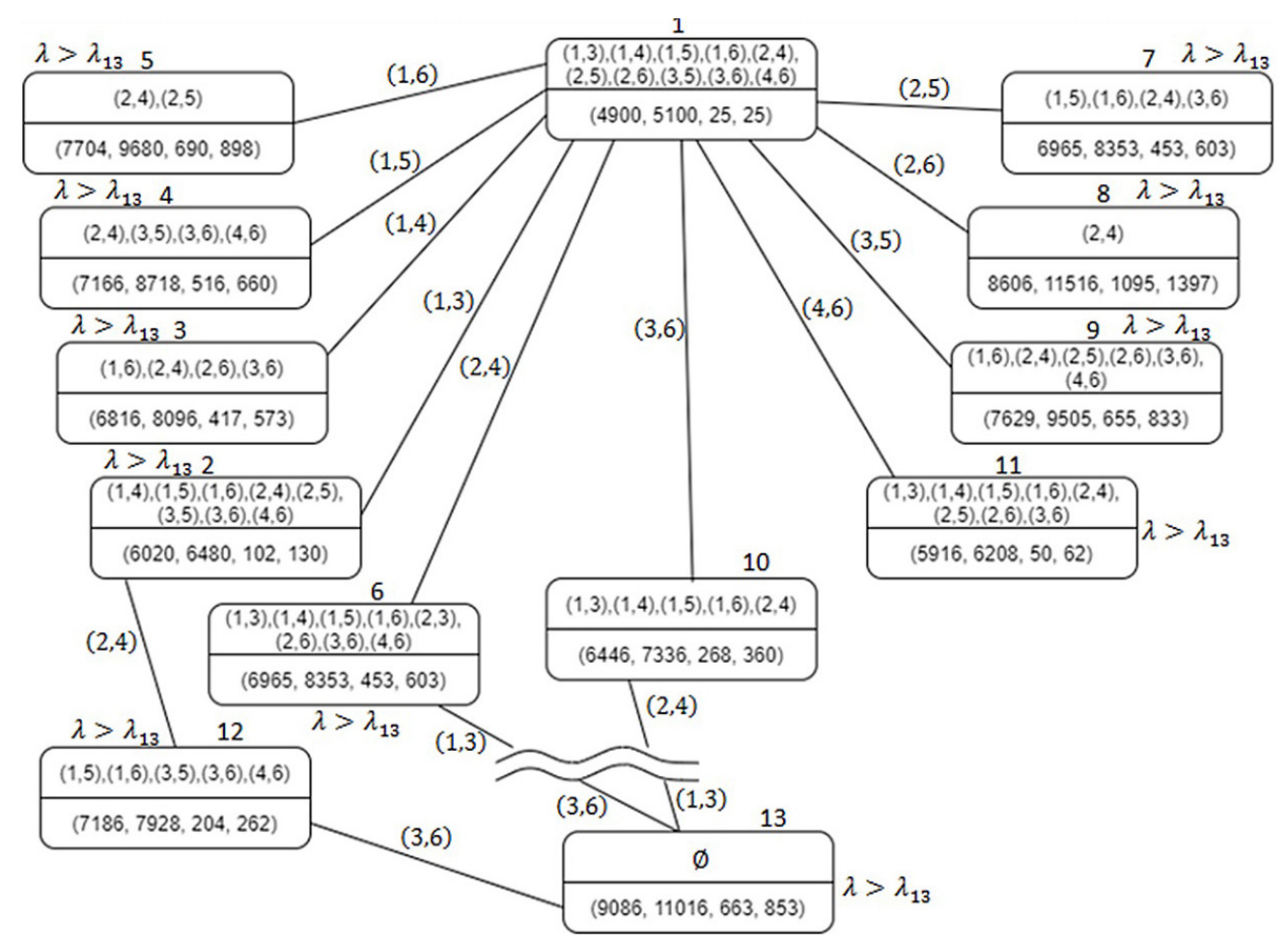

Figure 4. Solution tree 
we obtain vertices $2-11$ of the solution tree (Fig. 4) We define the sets of OD pairs for each vertex: Vertex 2

The value of the objective function for the set of OD pairs included in $N_{2}$ in vertex 2 is:

$$
\begin{gathered}
F\left(N_{2}\right) \sum_{i, j}\left((\mathrm{~cm})_{i j} n_{i j}+P_{i j} t_{i j}^{\Sigma}\right)= \\
\quad=(9727,14479,1790,2264)
\end{gathered}
$$

where: $N_{2}=N_{1} \cup(1,3)$.

When building the set of OD pairs $\widetilde{N}_{2}$, we check whether the OD pairs of set $\widetilde{N}_{1}$, not included in set $N_{2}$, satisfy the optimality condition (3). To this end, we create all possible sets of type $\lambda>$ $\lambda_{13}$ and determine the values of the objective function for them. Table 3 shows the results of these calculations for vertex 2 .

It follows from Table 3 that the OD pair $(2,6)$ does not satisfy the necessary condition, and so set $\widetilde{N}_{2}$ contains the following OD pairs $(1,4)$, $(1,5),(1,6),(2,4),(2,5),(2,6),(3,5),(3,6),(4,6)$. The estimate value is:

$$
\begin{gathered}
\lambda_{2}=\lambda\left(G_{2}\right)=\sum_{i, j}(c m)_{i j} n_{i j}\left(N_{2}\right)+ \\
+\sum_{i, j} P_{i j} t_{i j}^{\Sigma}\left(N_{2} \cup \widetilde{N}_{2}\right)=(6020,6480,102,130)
\end{gathered}
$$

The calculations for vertex 3-13 are made in an analogous manner.

\section{Step k-1}

We select a vertex to be branched. Because vertex 2 has the lowest estimate value, it is branched, as a result of which we obtain vertex 12 by adding the OD pair $(2,4)$ to set $N_{2}$.

\section{Step k}

We select a next vertex to be branched. Vertex 13 has the lowest lower bound estimate of the objective function and also has an empty set of OD pairs. Given all this, the optimal railroad blocking plan consists of the following direct OD pairs $N$ $=\{(1,3),(2,4),(3,6)\}$, and the value of the objective function is $F=(9086,11016,663,853)$ wagon-hours.

\section{CONCLUSIONS}

In a general case, wagon flows can be managed in an environment of approximate initial data. These data do not have specific values, but can be classified into certain confidence intervals.

In this paper, was presented a model for planning wagonload freight transport in which the numbers of wagons, wagon-hour savings and wagon-hours of accumulation were given by $(\mathrm{L}-\mathrm{R})$ fuzzy intervals. The fuzzy objective function optimization algorithm developed in this study is based on the branch-and-bound method, with bound estimates also presented as $(\mathrm{L}-\mathrm{R})$ fuzzy intervals. The estimates are compared, and the smallest estimate is chosen using four "possibility/necessity of fuzzy event" indices. In the case of $(\mathrm{L}-\mathrm{R})$ fuzzy intervals, these indices are determined by finding the points of intersection of their membership functions.

In real-life practice, the algorithm proposed in this paper is particularly useful for solving largescale problems. Calculations can be done taking into account poorly formalized maintenance factors by using dialogue at the elimination stage.

Importantly, the algorithm allows to evaluate the optimality of solutions obtained using any other method of planning wagonload freight transport.

\section{REFERENCES}

1. Acuña-Agost R. Mathematical modeling and methods for rescheduling trains under disrupted operations. Université d'Avignon; 2009. http:// https:// tel.archives-ouvertes.fr/tel-00453640

2. Brumercikova E., Sperka A. Problems of Access to Services at Railway Stations in Freight Transport in the Slovak Republic. Sustainability. 2020;12(19):8018. https://doi.org/10.3390/ su12198018

3. Cisowski T. The development of mobile transport on the example of Gdansk Airport. Autobusy: technika, eksploatacja, systemy transportowe. 2019;20(6):291-296. DOI 10.24136/ atest.2019.166

4. Cisowski T., Stokłosa J. Traffic prognose in transportation region. TTS Technika Transportu Szynowego. 2014;21(9): 36-38.

5. Dolinayova A., Zitricky V., Cerna L. DecisionMaking Process in the Case of Insufficient Rail Capacity. Sustainability. 2020;12(12):5023. https:// doi.org/10.3390/su12125023

6. Ivanovich-Ivakhin A., Viktorovich-Kotiaev D., Babeł M. The use of electric current in diesel locomotive systems with electric transmission for increase the adhesion of the vehicle wheels - railt. TTS Technika Transportu Szynowego. 2020;27(3-4):53-57.

7. Jacyna M., Gołębiowski P., Krześniak M., Szkopiński J., Organization of railway traffic. Wydawnictwo Naukowe PWN; 2019.

8. Jacyna M., Wasiak M., Lewczuk K., ChamierGliszczyński N., Dąbrowski T., Decision Problems in Developing Proecological Transport System. 
Rocznik Ochrona Środowiska. 2018;20:1007-1025.

9. Kampf R., Lorincová S., Hitka M., Stopka O. Generational Differences in the Perception of Corporate Culture in European Transport Enterprises. Sustainability. 2016;9(9):55-61. DOI: 10.3390/su9091561

10. Lesiak P. Inspection and Maintenance of Railway Infrastructure with the Use of Unmanned Aerial Vehicles. Problemy Kolejnictwa. 2020;188:115-127.

11. Lesiak P., Podsiadło R. Simulation of geometric pattern of surface flaws in railway rails. Przegląd Komunikacyjny. 2019;74(6):14-18.

12. Małek A., Caban J., Wojciechowski Ł. Charging electric cars as a way to increase the use of energy produced from RES. Open Engineering. 2020;10(1):98104. https://doi.org/10.1515/eng-2020-0009

13. Rakhmangulov A., Kolga A., Osintsev N., Stolpovskikh I., Sładkowski A. Mathematical Model of Optimal Empty Rail Car Distribution at Railway Transport Nodes. Transport Problems. 2014;9(3).

14. Stokłosa J., Liščák Š., Jaśkiewicz M., Ludwinek K. Intermodal transport system - development directions in the European experience. Logistyka. 2014;6:10070-10074.

15. Velarde J.M., García S., López M., Bueno-Solano A. Implementation of a Mathematical Model to Improve Sustainability in the Handling of Transport Costs in a Distribution Network. Sustainability. 2020;12:63. https://doi.org/10.3390/su12010063

16. Vojtek M., Kendra M., Zitrický V., Široký J. Mathematical approaches for improving the efficiency of railway transport. Open Eng. 2020;10:57-63. https://doi.org/10.1515/eng-2020-0008

17. Xu W., Zhang B., Deng Y., Wang Z., Jiang Q., Yang L., Zhang J. Corrosion of rail tracks and their protection. Corrosion Reviews. 2021;39(1):1-13. https://doi.org/10.1515/corrrev-2020-0069

18. Bojarczak P., Lesiak P. UAVs in rail damage image diagnostics supported by deep-learning networks. Open Engineering. 2021;11(1):339-348. https:// doi.org/10.1515/eng-2021-0033

19. Wang J. The Research on Efficiency and Effectiveness of Rail Transport. IERI Procedia. 2012;3:126130. https://doi.org/10.1016/j.ieri.2012.09.021

20. Kozłowski M., Pawełczyk M., Piotrowska-Piątek A. Innovativeness of railway transport in the context of the development of tourism in Poland. Qual Quant. 2020;54:1691-1703. https://doi. org/10.1007/s11135-019-00928-z

21. Abramović B., Zitricky V., Biškup V. Organisation of railway freight transport: case study CIM/SMGS between Slovakia and Ukraine. Eur. Transp. Res. Rev. 2016;8:27. https://doi.org/10.1007/s12544016-0215-7

22. Dolinayova A., Cerna L., Zitricky V. The Role of Railway Transport in East-West Traffic Flow Con- ditions of the Slovak Republic. In: Sładkowski A. (eds) Transport Systems and Delivery of Cargo on East-West Routes. Studies in Systems, Decision and Control. 2018;155. Springer, Cham. https://doi. org/10.1007/978-3-319-78295-9_3

23. Nie Y., Zhu X. Study on the Method of Passenger Transport Organization in Peak-Hour of Railway Station. In: Jia L., Qin Y., Suo J., Feng J., Diao L., An M. (eds) Proceedings of the 3rd International Conference on Electrical and Information Technologies for Rail Transportation (EITRT) 2017. EITRT 2017. Lecture Notes in Electrical Engineering. 2018;483. Springer, Singapore. https://doi. org/10.1007/978-981-10-7989-4_60

24. Dolinayova A., Danis J., Cerna L. Regional Railways Transport-Effectiveness of the Regional Railway Line. In: Fraszczyk A., Marinov M. (eds) Sustainable Rail Transport. Lecture Notes in Mobility; 2019. Springer, Cham. https://doi. org/10.1007/978-3-319-78544-8_10

25. Zhang R. Route planning model of rail transit network facing the railway freight transport deadline. Int J Syst Assur Eng Manag; 2021. https://doi. org/10.1007/s13198-021-01067-1

26. Thaduri A., Aljumaili M., Kour R. et al. Cybersecurity for eMaintenance in railway infrastructure: risks and consequences. Int J Syst Assur Eng Manag. 2019;10:149-159. https://doi.org/10.1007/ s13198-019-00778-w

27. Blainey S.P., Armstrong J., Smith A.S.J. et al. New routes on old railways: increasing rail's mode share within the constraints of the existing railway network. Transportation. 2016;43:425-442. https:// doi.org/10.1007/s11116-015-9582-5

28. Mirzabeiki V., Holmström J., Sjöholm P. Aligning organisational interests in designing rail-wagon tracking. Oper Manag Res. 2012;5:101-115. https://doi.org/10.1007/s12063-012-0072-z

29. Tang Z., Sun J. Multi objective optimization of railway emergency rescue resource allocation and decision. Int J Syst Assur Eng Manag. 2018;9:696702. https://doi.org/10.1007/s13198-017-0648-y

30. Söderholm P., Karim R. An enterprise risk management framework for evaluation of eMaintenance. Int J Syst Assur Eng Manag. 2010;1:219. https:// doi.org/10.1007/s13198-011-0046-9

31. Hosseini A., Sahlin T. An optimization model for management of empty containers in distribution network of a logistics company under uncertainty. J Ind Eng Int. 2019;15:585-602. https://doi. org/10.1007/s40092-018-0286-2

32. Huang C., Huang Y. Research and design of data communication subsystem of urban rail transit CBTC system. Int J Syst Assur Eng Manag; 2021. https://doi.org/10.1007/s13198-021-01055-5

33. Thaduri A. Nowcast models for train delays based 
on the railway network status. Int J Syst Assur Eng Manag. 2020;11,184-195. https://doi.org/10.1007/ s13198-020-01002-w

34. Dedík M., Čechovič L., Gašparík J. Methodical Process for Innovative Management of the Sustainable Railway Passenger Transport. Transportation Research Procedia. 2020;4:305-312. https://doi. org/10.1016/j.trpro.2020.02.038

35. Frantasov D., Kudryashova Y., Information and Measurement System for Electric Power Losses Accounting in Railway Transport. Transportation Research Procedia. 2021;552-558. https://doi. org/10.1016/j.trpro.2021.02.107

36. Gerhátová Z., Zitrický V., Klapita V. Industry 4.0 Implementation Options in Railway Transport. Transportation Research Procedia. 2021;53:23-30. https://doi.org/10.1016/j.trpro.2021.02.003

37. Zhang R., Li L., Jian W. Reliability analysis on railway transport chain, International Journal of Transportation Science and Technology. 201;8(2):192201. https://doi.org/10.1016/j.ijtst.2018.11.004.

38. Papoušková K. The Concept of Railway Transport in the Czech Republic. Transportation Research Procedia. 2021;53:154-158. https:/doi. org/10.1016/j.trpro.2021.02.020.
39. Nedeliaková E., Hranický M.P., Čechovič L. Possibilities of implementing satellite navigation elements in the field of railway transport. Transportation Research Procedia, 2019;40:1504-1509. https://doi.org/10.1016/j.trpro.2019.07.208.

40. Pietrzak O., Pietrzak K. The role of railway in handling transport services of cities and agglomerations. Transportation Research Procedia. 2019;39:405-416. https://doi.org/10.1016/j. trpro.2019.06.043

41. Jarocka M., Glińska E. The State and Prospects for Development of Railway Transport Infrastructure in Eastern Poland - Secondary Data Analysis. Procedia Engineering. 2017;182:299-305. https://doi. org/10.1016/j.proeng.2017.03.198

42. Krasoń W., Niezgoda T., Stankiewicz M. Innovative Project of Prototype Railway Wagon and Intermodal Transport System. Transportation Research Procedia. 2016;14:615-624. https://doi. org/10.1016/j.trpro.2016.05.307

43. Seidenglanz D., Taczanowski J., Król M., Horňák M., Nigrin T. Quo vadis, international long-distance railway services? Evidence from Central Europe. Journal of Transport Geography. 2021; 92:102998. https://doi.org/10.1016/j.jtrangeo.2021.102998 